\title{
15. Political and Media Leadership in the Age of YouTube
}

\section{Stuart Cunningham}

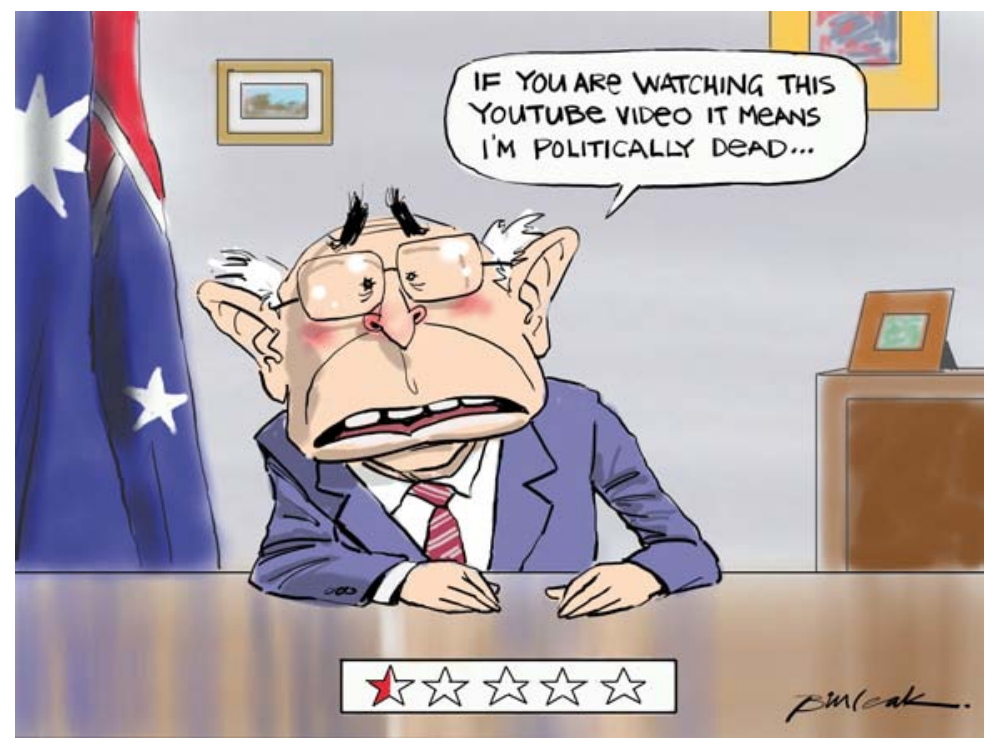

\section{Introduction}

In this chapter, I will track the key academic traditions that inform the field of media-politics relations. I will then argue that the way in which both political science and media and communications academic traditions approach the politics-media relationship — an 'inter-elite' account — is being eroded by contemporary developments in internet affordances, especially around the blogosphere, citizen journalism and the extent of 'virtual' public communication. The implications of these trends for political leadership and the media-politics relationship, focusing on some relevant developments during the 2007 Australian Federal election campaign, are then briefly explored.

\section{Understanding the media-politics nexus: academic traditions}

The media and politics literature has a venerable tradition. It dates from Harold Lasswell in the 1930s and his fundamental model of public communication as 'who says what, in which channel, to whom, and with what effect?' This highly influential model, psychologistic, individualistic and linear, was complicated by the work of Paul Lazarsfeld and his colleagues (Lazarsfeld et al. 1944[1969]) at the Bureau of Applied Social Research when they hypothesised a 'two step' 
flow between influencers like politicians - and the media in general — and the public. The role of opinion leaders became crucial in a less deterministic and complex model of public communication.

This forms part of a broader media and politics-effects studies tradition. It can be characterised as politico-centric (rather than media-centric) and focussed on political 'management' — the modernist assumption of political leaders' management of media in a close but controlled symbiosis. I would characterise this tradition as political science based on an 'inter-elite' model, which finds accomplished proponents in Australia in the work of, for example, Ian Ward (1994), Rod Tiffen (1989; 1999; 2001) and Murray Goot (Goot and Tiffen 1992).

A canonical work in this tradition is Tiffen's News and Power (1989). News and Power follows this tradition even as it complicates it. While the power of media to directly influence public opinion, and the power of media owners to control media content, are both overstated according to Tiffen (2006: 41), the analytical attention is on those ways, systemic as well as highly personal, that political and media elites interact for mutual advantage, deal making and power-assertion and, where necessary, power-sharing.

News and Power analyses the mechanism of inter-elite power and concentrates on the clashes of the elites - where elite interests do not align. In a contemporary setting, this would explain the government's inactions over more than a decade on media ownership changes - mooted twice and abandoned before there was finally some change in 2006-7. Another good example would be pay television policy in Australia, where the interests of the media elites clashed directly (Murdoch wanting it, Packer opposing it) such that political decision making was stymied for many years.

In the media and communication studies tradition, there is also a modernist school. Works such as Julianne Schultz's Reviving the Fourth Estate (1998) and Graeme Turner's Ending the Affair (2005) are good examples in this tradition. Turner's Ending the Affair is a history of current affairs television in Australia which decries the loss of its fourth estate function and argues that the only way forward for this media format is to recover such a function. Political leadership is able to escape close, sceptical scrutiny as a result of this decline, and the Australian polity and the intellectual and ethical provenance of Australian journalism is the poorer for it.

There is also a post-modernist tradition in media and communications studies which finds its partial mirror in varieties of post-modernist political science. Whereas the modernists see the contemporary Western public sphere having been tarnished or even fatally compromised by the encroachment of commercial media and communications, the postmodernists see the media having become the main, if not the only, vehicle for whatever can be held to exist of the public sphere in such societies. Such 'media-centric' theorists within these fields can 
hold that the media actually envelop the public sphere. For John Hartley (1999: 217-8):

The 'mediasphere' is the whole universe of media ... in all languages in all countries. It therefore completely encloses and contains as a differentiated part of itself the (Habermasian) public sphere (or the many pubic spheres), and it is itself contained by the much larger semiosphere ... which is the whole universe of sense-making by whatever means, including speech ... [It] is clear that television is a crucial site of the mediasphere and a crucial mediator between general cultural sense-making systems (the semiosphere) and specialist components of social sense-making like the public sphere. Hence the public sphere can be rethought not as a category binarily contrasted with its implied opposite, the private sphere, but as a 'Russian doll' enclosed within a larger mediasphere, itself enclosed within the semiosphere. And within 'the' public sphere, there may equally be found, Russian-doll style, further counter-cultural, oppositional or minoritarian public spheres.

Hartley's topography has the virtue of clarity, scope and heuristic utility, even while it remains provocatively media-centric. This is mostly due to Hartley's commitment to the strictly textual provenance of public communication, and to his interest in Lotman's notion of the semiosphere, more so than Habermas's modernist understanding of the public sphere standing outside of and even over and against its 'mediatisation'.

Such programmatic postmodernism comes to appear quite prescient when set against contemporary accounts of the realpolitik of political leadership. Tony Blair's seventh and final plenary address in the 'Our Nation's Future' series just before he stepped down (http://www.number-10.gov.uk/output/Pagel1923.asp) was about politics and the media. He lamented that no matter how available and open government/leadership is today, it doesn't matter, because of the way politics is reported — with exponentially increasing rhetorics of conflict, suspicion and cover up. The necessity for the modern political leader to lead through and for the media interface, aligning their style or persona with the protocols of 'politicotainment' (Riegert 2007), is the stuff of contemporary journalistic accounts of the modern political leader.

An Australian political leader who exemplified this approach was Queensland Premier Peter Beattie. Rather than a command-and-control 'management' of media through the calculated soundbite and the photo opportunity and carefully orchestrated rounds of the AM talk radio stations (a practice once thought mandatory and indeed cutting-edge in the 1990s and brought to temporary perfection by Prime Minister Howard), Beattie embodied the idea that 'you get to know your pollies in roughly the same fashion you get to know TV personalities' (Burchell 2007). This meant a focus on FM youth radio and light 
entertainment TV formats and 'politicians-as-everyday people' interactions demonstrating that they had a life outside politics. 'All this casualness and nonchalance, needless to say, took a fearsome amount of training and self-discipline' (Burchell 2007).

One of the important works of political science in the postmodernist tradition is Stephen Coleman's A Tale of Two Houses $\left(2003^{1}\right)$, which compares unflatteringly 'political junkies' with 'Big Brother' watchers. The former group, the 'PJs', exhibited more hierarchical and traditional attitudes to political participation, scorning the relevance of reality television's take on plebiscitary democracy (for example, audience voting on Big Brother evictees), while the BBs were more accepting of the relevance of PJ culture while typically not sharing it themselves. Coleman argues that mainstream politics could learn a great deal from the plebiscitary provenance of popular reality shows for the light they shed on contemporary forms of engagement with audiences, fans, communities, and constituencies.

Essentially, though, the modernist and postmodernist traditions are in broad agreement about the objects of analysis: mainstream media and its representational power in relation to the prospects for political leadership and political management. Their differences: on the one hand the modernists seek to countervail or balance the power of the state with the power of the media, and on the other the postmodernists analyze the subsumption of the political domain by a more media-centric focus than is traditional.

\section{The dilemma for politics and media}

Today we find that, even as the media's capacity to countervail or subsume political reality is either decried or extolled, the media's capacity to deliver this representational envelope is being eroded by the rise to political prominence of the blogosphere, citizen journalism and the burgeoning extent of 'virtual' public communication. The now irresistible array of new communicative activity engendered by new digital technologies has reached a stage where mainstream media and political leadership can no longer deny or avoid it, or indeed operate effectively without engaging with it.

The power bases - on both sides of the elite equation - are changing. As Charles Leadbeater (2007) puts it:

... formal party politics is an industry in decline. In the late 19th century, people campaigned in their millions to be allowed into political processes that were dominated by elites. Little more than a century later and the disenchanted great-grandchildren of those campaigners are flooding out of the political realm as fast as they can ... people talk of their political representatives as invisible, alien, partisan, arrogant, untrustworthy, irrelevant and disconnected. Industrial-era mass media - newspapers 
and television - suffer from serious weaknesses as vehicles for democratic life. They have high fixed costs (printing plants and television studios) so they have to reach mass markets to earn their keep. As a consequence they treat people as an audience to be titillated rather than citizens who have a responsibility to engage in debate.

The dilemma is that contemporary political leadership must deal with the broad trends away from political engagement through embracing new means of socially-networked communication which are largely unable to be controlled in the time-honoured way of conventional politics.

The irony is that, as Westminster politics becomes more presidential, with its concentration of power in the executive and election campaigns more and more obsessively focussing on the leaders alone, the more new social media platforms are opening up the hyperlocal and the 'neo-demos'. And these are driving each other, as the mainstream media power base is being challenged by reader decline, the blogosphere and the blurring of the line between professional and citizen journalism. The inter-elite model, on which both media and communications studies and political science traditions have relied for decades, is coming into question.

The mainstream media (dubbed 'MSM' in the blogosphere) seek to speed up the political cycle, and ratchet up the 'politicotainment', in good part because of the competition they face from a wellspring of user-generated content and communication that is beginning to shoulder aside the traditional professional sources of public communication together with the commercial business models 'big' media are built on. Big media are especially sensitive to this perceived incursion onto its own turf and react, in general, very badly to it. In play and at stake are time-honoured notions of professionalism, the fourth estate function and centralised, one-to-many communication paradigms versus networked, planar, paradigms, to say nothing of their bottom lines. During the long pre-campaign period in 2007, the 'July 12' incident (when The Australian blew its stack over the blogosphere's better analysis of its own Newspoll data) stood out as the low point of a simmering stand-off between MSM and its bothersome 'other' (see Flew 2008).

But of course, leaders, governments and bureaucracies also react badly. The litany of missed opportunities, wrongheaded schemes and just plain failures to engage positively with online worlds and the dynamics they unleash speak fulsomely: Howard Dean's rise and fell on the back of online opinion in the last US Presidential campaign, Mark Latham's failed experiment in localism through e-democracy, and top-down communication strategies by bureaucracies using online simply as another linear 'consultation' medium, are a few examples. 
Margaret Simons' The Content Makers (2007), and her regular Crikey and other posts, are an important response to these trends. Her starting point is this erosion of media power (the end of the 'imperial age'), but what is different is the practicality of her response, which is to lead hyperlocal initiatives such as The Map in Flemington and to warn that good quality journalism never paid its way and that the 'creative destruction' of news organisations' business model may bring about the demise of adequately paid, quality journalism.

Professional journalism and the internet have existed peaceably for more than a decade but now it is very hard to do so. There is an erosion of inter-elite symbiosis and, while these changes are never as abrupt and revolutionary as the utopian or dystopian rhetoric would suggest, and shifts in the balance are more in evidence in US politics than in Australia, there is a more planar sense of the distribution of influence than previously. The blogosphere lays claim that they are the true inheritors of the fourth estate function, as they are increasingly, and competently, critical of the degree to which mainstream media performs this function.

But the fact is that there is a great degree of porosity between citizen journalism and mainstream journalism. It is still the case that to become well known in the blogosphere you must break stories and breaking stories involves strategic and successful interactions with mainstream media. At this stage there has been greater impact registered by the new social media and the blogosphere in mainstream media than in politics. However, this is changing, as the 2007 Federal election campaign began to demonstrate clearly.

\section{The 2007 Federal election campaign: contrasts in leader projection}

While the 2007 Federal election campaign was 'not yet the internet election' (Flew 2008), it may have constituted an intriguing confluence of the 'coming of age' of the Australian blogosphere (Simons 2008) and evidence of the relative success and failure of the opposing campaigns - and especially their leaderships - in developing a 'politics 2.0' (which takes account of both the threats and affordances of web 2.0).

The incumbent Howard government went into the almost year-long pre-campaign as well as the campaign proper without a developed strategy to engage with online and web 2.0 platforms and services. This was exemplified in Howard's initial foray into the world of YouTube as he appeared in prime ministerial stand-and-deliver style behind his office desk with the flag as backdrop and addressed his 'audience' with a TV-radio real time-based 'Good Morning'. This was to deliver a speech on climate change - the issue which many Howard ministers and commentators believed was the single most important issue that 
changed votes, especially amongst younger voters. It might not have been possible to choose a more difficult topic to start one's YouTube career!

The received wisdom is that political communicators 'use' social networking and other web 2.0 sites not primarily because they want to reach the main users of those sites, but because journalists pay attention to them and this is a way of securing their attention. But this too-clever-by-half strategy was undercut by the deluge of criticism, savage satire and - perhaps worst of all when set against the original intent - mainstream media reportage of what had become a minor cause celebre within a few days.

On the Labor side, the relative success of the Labor online strategy stands in stark contrast. Matthew Hindman's (2007: 12) argument is that the largest impact of the internet on politics has been, to date, on the 'backend' of politics. While there has been great emphasis placed on the breakthrough business models of online retailers such as Amazon and eBay, most businesses have 'quietly used the internet and related information technologies to streamline operational logistics and generally make business processes more efficient'. He suggests that political practice is likely to mirror this process, with the internet being more important in the 'campaign for resources' than the 'campaign for votes'.

The Kevin07 campaign exemplified this, and more. ${ }^{2}$ The campaign motto, Kevin07, with its simultaneously self-mocking and self-bolstering allusions to 'James Bond 007' (given the image of Rudd as a nerd and bureaucrat), and its marginalisation of the party in favour of presidential 'New Leadership', both centred the campaign on the leader and, in Camilla Cooke's term, 'humanised' him. Cooke, media manager of the Kevin07 campaign website, has a commercial digital marketing background and brought this experience to the campaign. The ALP, she argued, 'embraced' online campaigning, 'seeing it as an opportunity to communicate and have a dialogue'. They 'broke new ground', dealing with the more open space of blogging, MySpace, and YouTube. The backend use of the website was critical, but it was not only about the campaign for resources but as much if not more about reinforcing those already disposed to vote for Rudd that this side of politics was more on their wavelength than was the other side.

The Kevin07 campaign has been compared (by, for example, George Megalogenis on his blog Meganomics) to Barack Obama's Presidential campaign in two key aspects. First is the ability to generate resources built up from small contributions accessed by 'long tail' (Anderson 2006) principles of aggregation that the internet facilitates. Second is that Rudd, like Obama, had been able to secure the youth vote and this, more than any other single demographic, may have been determinative in winning the 2007 election.

Camilla Cooke reports that the Kevin07 website was not prepared for the amount of backend traffic the campaign generated. The sales of Kevin07 T-shirts and 
associated paraphernalia were far more successful than anyone had planned. The vast majority of website traffic up to the last weeks of the campaign was from those under forty, and who were confirmed in their voting intentions. The experience provided by the website was to 'make them excited, feel part of the campaign'. A large and growing body of online supporters had a 'ripple effect', reinforcing the image of youth vote turning to Rudd and bolstering the campaign coffers on the long tail model.

But there was also a major upswing in traffic to the site in the final weeks of the campaign (see Alexa 2007), far greater than any other campaign website. These were not decided voters and visited for far less time. What they were presented with upfront, at that stage, were short web camera coverage of ALP leaders 'something more charming than a policy document' - which made 'the whole thing seem more domestic', according to Cooke.

The online political culture during the long campaign period also featured some highly creative and popular art and commentary screening on YouTube that underlines the extent to which alternative, informal arenas have opened up outside television and live performance venues. Hugh Atkin's 'Chinese Propaganda' online video, a brilliant satire of Mandarin-speaking Rudd's rapid rise to power, was reputedly accessed by a quarter of a million viewers in the lead up to the election. Stefan Sojka's 'Bennelong Time Since I Rocked and Rolled' satirises Howard to the tune of the Led Zeppelin classic. Killerspudly's series 'John Howard: Search for a Scapegoat', followed a puppet figure Howard seeking 'something special to scare the people into voting for me'. For Atkin, 'the internet is a far better barometer of generation $\mathrm{Y}^{\prime}$ 's engagement with politics than a head count at a rally' (Wilson 2008).

\section{Final remarks}

What does this presage for notions of political and media leadership? The new social media and the arena of light entertainment favoured by younger citizens, and the blogosphere (which is much more a sphere which skews older and professional than the general population), are not unitary phenomenon. They present opportunities for formal political leadership but these opportunities can only be grasped if traditional command-and-control strategies are rethought. They both facilitate access to a hard-to-reach younger demographic and can enhance their exposure as they make themselves more accessible, and constrain standard issue politics by upsetting the old inter-elite modes of engagement. They also have facilitated emergent, alternative, forms of political communication and leadership.

What of media leadership? Mainstream media will need to work with the blogosphere rather than attempting to stand over against it as the primary authoritative source of news and information. In Margaret Simon's estimation: 
... the media model of the future will be pro-am a small core of media professionals surrounded by, supported and critiqued by a swarm of amateurs who will be both audience and colleagues. If professional journalists are 'gatekeepers', able to decide what gets reported and how, they are now going to have to learn to live with increasingly active 'gatewatchers' (Bruns 2007), who will both critique what journalists do, and generate their own, different, material.

\section{References}

Alexa, 2007, 'Traffic History Graph for kevin07.com.au', Alexa The Web Information Company, http://www.alexa.com/data/details/traffic_ details/kevin07.com.au?site $0=$ kevin07.com.au\&site $1=$ liberal.org.au\&site $2=$ nationals.org.au\&site $3=$ greens.org.au $\&$ site $4=$ d e m ocrat s.org. a u \& y $=r \& z=3 \& h=400 \& w=700 \&$ $\mathrm{u} \% 5 \mathrm{~B} \% 5 \mathrm{D}=$ kevin07.com.au\&u $\% 5 \mathrm{~B} \% 5 \mathrm{D}=$ liberal.org.au $\& \mathrm{u} \% 5 \mathrm{~B} \% 5 \mathrm{D}=$ nationals.org.au \&u \% 5 B \% 5D=greens.org.au \&u \% $5 \mathrm{~B} \% 5 \mathrm{D}=$ democrats.org.au $\& \mathrm{x}=2008-03-25$ T06\%3 A $26 \% 3$ A $25.000 Z \&$ check $=$ www.alexa.com $\&$ signature $=$ VWlowMl $\% 2$ FThwUfzPOY $5 \mathrm{uEOLy} 31 \%$ $2 \mathrm{Fk} \% 3 \mathrm{D} \&$ range $=6 \mathrm{~m} \&$ size $=$ Large (last accessed November 2007).

Anderson, Chris, 2006, The Long Tail: Why the Future of Business Is Selling Less of More, New York: Hyperion.

Bruns, Axel, 2007, Gatewatching: Collaborative Online News Production, New York: Peter Lang.

Coleman, Stephen, 2003, 'A Tale of Two Houses: The House of Commons, the Big Brother House and the People at Home', Parliamentary Affairs, 56:4, pp. 733-58. See also A Tale of Two Houses http://www.hansardsociety.org.uk/publications/recent/bigbrother

Cooke, Camilla, 2007, Interview conducted by Jason Wilson, 17 December 2007.

Flew, Terry, 2008, 'Not Yet the Internet Election: Online Media, Political Commentary and the 2007 Australian Federal Election', Media International Australia, 126, pp. 5-13.

Goot, Murray and Rodney Tiffen, 1992, (eds), Australia's Gulf War, Carlton, Vic.: Melbourne University Press.

Hartley, John, 1999, Uses of television, London: Routledge.

Hindman, Matthew, 2007, Voice, Equality and the Internet (draft ms) http://www.matthewhindman.com/ (last accessed 11 April 2008).

Lazarsfeld, Paul F., Bernard Berelson and Hazel Gaudet, 1944 [1969], The People's Choice: How the Voter Makes Up His Mind in a Presidential Campaign, $3^{\text {rd }}$ ed, New York and London: Columbia University Press. 
Leadbeater, Charles, 2008, 'Democracy in the network age: time to WeThink', http://www.opendemocracy.net/article/charles_leadbeater/WeThink (accessed 10 April).

Leadbeater, Charles, 2007, We-Think: Mass Innovation not Mass Production, Profile Books.

Riegert, Kristina (ed.), 2007, Politicotainment: Television's Take on the Real, New York, Peter Lang.

Schultz, Julianne, 1998, Reviving the Fourth Estate: Democracy, Accountability and the Media, Melbourne: Cambridge University Press.

Simons, Margaret, 2007, The Content Makers: Understanding the Media in Australia, Camberwell: Penguin Books.

Simons, Margaret, 2008, 'New Media Lessons from Election 07', http://www.crikey.com.au/Media-Arts-and-Sports/20080410-New-media-lessonsfrom-Election-07.html 10th April (accessed 10 April 2008).

Coleman, Stephen, 2006, 'How the other half votes: Big Brother viewers and the 2005 general election', International Journal of Cultural Studies, 9:4, 457-79.

Tiffen, Rodney, 1989, News and Power, Sydney: Allen \& Unwin.

Tiffen, Rodney, 1999, Scandals: Media, Politics and Corruption in Contemporary Australia, Sydney: UNSW.

Tiffen, Rodney, 2001, Diplomatic Deceits: Government, Media and East Timor, Sydney: UNSW Press.

Tiffen, Rodney, 2006, 'Political economy and news', in S. Cunningham ans G. Turner (eds) The Media and Communications in Australia, Sydney: Allen and Unwin, pp. 28-42.

Turner, Graeme, 1998, Ending the Affair: The Decline of Television Current Affairs in Australia, Sydney: UNSW Press.

Ward, Ian, 1994, Politics of the Media, South Melbourne: Macmillan Education Australia.

Wilson, Lauren, 2008, 'Mouse clique that roars', The Weekend Australian Review, 5-6 April, p. 6.

\section{ENDNOTES}

${ }^{1}$ Coleman (2006) has extended his analysis to cover the latest UK general election in 2005.

2 Some of the following analysis is taken from an interview conducted by Jason Wilson with Camilla Cooke, online campaign consultant for the ALP, and manager of the Kevin07 website, 17 December 2007. 